\title{
Drug Users as Stakeholders in Drug Policy: Questions of Legitimacy and the Silencing of the Happy Drug User
}

\author{
Anna Ross
}

Calls for 'evidence-based policy' and greater community 'participation' are often heard in the drug policy field. Both movements are in different ways concerned with the same questions about how 'drug problems' ought to be governed and the place of 'expertise' and 'engagement' in democratic societies. However, these calls rely on the assumption that knowledges, publics, expertise, and issues of concern are fixed and stable, waiting to be addressed or called to action, thus obscuring ontological questions about what 'participation' (be that lay or expert) may do or produce. There has been limited research in the drugs field that has taken 'participation' as an object of study in itself and through critical examination attempted to open up new possibilities for its remaking.

(Lancaster et al., 2018, p. 351)

\section{Introduction}

In 2014, I started a PhD in drugs policy at the University of Edinburgh. My interest in the area was personal. As a woman (and now a mother) who uses drugs, and has done since the age of 14 , I have been at the sharp end of drug policy decisions for 26 years. Throughout these years, I have experienced multiple drug-using communities and witnessed the impact criminal sanctions have on these communities. I have friends who have been imprisoned, stigmatised and died as a result of their drug use. I have internalised a deviant persona as a result of decades of being a criminal in the eyes of society. However, the biggest driver for me was the

\footnotetext{
The Impact of Global Drug Policy on Women: Shifting the Needle, 237-246 Copyright $(\mathcal{C} 2021$ by Anna Ross These works are published under the Creative Commons Attribution (CC BY 4.0) licence. Anyone may reproduce, distribute, translate and create derivative works of these works (for both commercial and non-commercial purposes), subject to full attribution to the original publication and authors. The full terms of this licence may be seen at http://creativecommons.org/licences/by/4.0/legalcode doi:10.1108/978-1-83982-882-920200033
} 
belief that the drug laws do not work. They do not prevent drug use, they actively create much of the harm they purport to prevent, and they are an infringement on our cognitive liberty to alter our own consciousness (Center for Cognitive Liberty and Ethics (CCL), 2004). Furthermore, as I became more involved in the drug policy debate, it was evident that it was not only drug consumers that felt they did not work. By 2014, there had been two significant independent reports on UK drug policy and its failure (The Royal Society for the encouragement of Arts Manufactures and Commerce (RSA), 2008; UKPDC, 2012). I was therefore passionate about exploring why, in the face of national and international evidence, drug policy was not changing in the direction being put forward.

I initially set out to explore the link between evidence and policy. I set up the Scottish Drug Policy Conversations (SDPC) in order to explore this link, and to provide a space for different policy actors to engage with a wider stakeholder group, including drug consumers. It was through this group, and the networks I made as a result, that the focus of the research changed. I became involved in different policy advisory groups, and through this began to experience the different ways in which people are treated depending on their narrative of involvement. As a woman who uses drugs and has used many different drugs - both problematically and non-problematically - and now a professional, I found myself straddling many different personas in order to engage at different levels.

This chapter explores this engagement in order to explore what the barriers are for participation in drug policy. In doing so, critical drug theory emerges as a potential framework to challenge these barriers. It starts by introducing the concept of critical drug theory, a concept which is not new but has yet to be developed in-depth by the critical theory literature, or named as such. It then moves onto my participation in three different policy groups, exploring how easy or difficult it was to connect with policymakers from each group and my experience of participation. Finally, I set out the typography of participation; the different kinds of drug consumers and their perceived legitimacy in the policy process, which emerged from my engagement.

\section{Critical Drug Theory}

Critical drug theory is a theoretical framework that challenges the assumption that drug use inevitably causes harm. It asserts that drug use is a social phenomenon, and the cultural framing of drug use is a result of systemic narratives that have been used to justify policies and practices which disproportionately impact those whose ethnicity, social class, gender, religious, ideological and political viewpoints do not fit into the dominant narrative. It contends that drug policy is an oppressive framework that seeks to de-legitimise and stigmatise these groups, and that the narratives of drug harm and the medico/legal structures which surround drug use mean that evidence and participation are focussed on a small section of the drug-using population, namely problem drug use.

The focus on problem drug use has resulted in a focus on certain kinds of drug consumption, and a policy strategy to match that: recovery. As a result, only certain stakeholder views are taken into consideration when participation is being 
designed at an institutional level, and only certain discourse is considered legitimate. During my research, I separated these stakeholder engagements into four narratives: the professional, the sick, the recovered and the happy drug consumer. The legitimacy of these stakeholders is dependent on how they are involved and at what stage of the process. It will come as no surprise that the happy drug consumer is never invited to engage, and is in most instances not considered a legitimate voice.

\section{Engaging with Policy: A Participant's Journey}

I engaged with three different policy groups over the course of several years, each one representing a different aspect of drug use and participation. The first group I was engaged with and helped set up was the SDPC, a multi-stakeholder group with the aim of bringing different voices to the policy table to discuss drug policy reform.

The setting up of SDPC provides an insight into how non-traditional structures (independent from government funding, a broad range of stakeholders and the use of deliberative engagement methods) can participate in the policy arena: we were taken seriously because our participants were viewed as 'legitimate', and the way in which we engaged was non-confrontational. Our participants were pooled from a cross-section of stakeholders and included many of the 'same old faces'. Yet there were many non-traditional participants. As the convenor of SDPC, and a PhD candidate with professional experience in the public sector, I was able to approach senior figures in a range of institutional settings and be taken seriously. My own drug-using history was not known, and I was therefore considered an 'objective' broker between stakeholders. Generally speaking, I had little difficulty accessing policymakers and associated advisers and developed a personal relationship with members of the policy unit that enabled me to feedback the outcomes of SDPC, in the hope they would be used to help shape policy. Maintaining this relationship was more challenging.

As my personal drug use became more evident (through my own disclosure) my objective persona began to be questioned. Although the impact was subtle, and difficult to quantify, the involvement of institutional actors such as the police and the policy units started to become more difficult, and I found myself being slowly shut out. This involved ignoring emails and requests for participation, and a general arm's length behaviour when I met with institutional actors at various events. This became clearer through my involvement with the second policy group, the Medicinal Cannabis Reform Scotland group (MCRS).

I became involved with the campaign leader after liking a Facebook page set up to support the first meeting held by MCRS at the Scottish Parliament. They had managed to get several members of the Scottish Parliament and other interested parties to a meeting to discuss the movement towards a medicinal cannabis framework in Scotland, and I was impressed. I contacted her and suggested she become involved in SDPC, and she attended the SDPC session on cannabis. However, it became apparent that the best role for her was running the MCRS group and building momentum for that campaign. The campaign 
leader is a woman with fire, and she is doing it her way, which aggravates some people, alienates others, but in the end appears to get things done. She organised the first meeting, and I helped her set up the subsequent ones by connecting her with relevant institutional actors such as the Substance Misuse Unit, Police Scotland and the Crown Office and Procurator Fiscal Service. My role within this process provided the academic position, highlighting the legal and practical hurdles that needed to be overcome, and providing a link between the different stakeholders involved by chairing the meetings using SDPC principles of respectful dialogue. In addition, I identify as a cannabis user in both recreational and therapeutic capacities as a sleep aid and topical eczema treatment. This meant my persona in this process straddled both the professional, the happy and the sick drug user, terms that will be explored below.

Engagement with institutional actors was difficult from the start. Institutions like things to be done through their own protocols, and when stakeholders do not behave in the way they should, they are shut out. Stakeholders are expected to defer to authority, and when they do not they are considered troublemakers. The problem with this viewpoint is that most drug-using stakeholders are passionate about their topic, because it affects their lives so immediately: they are literally dying as a result of policy. Therefore, to expect calm and rational responses to institutional hurdles and barriers is unreasonable. I attempted to act as a broker between the MCRS and institutions such as the police and government, but it became clear that they were not keen to engage on the issue of medicinal cannabis and the user group. Unlike the SDPC, which was seen as a neutral space, engagement with MCRS was viewed as activism and lobbying.

As the hurdles increased and the frustration of those involved in MCRS intensified, my own ability to directly engage with the institutions became increasingly difficult. My professional identity became unstuck and I began to be viewed as a stakeholder, and therefore someone with a vested interest in the outcomes. This experience is contrasted with the final group I was involved in, the Lived and Living Experience Executive group (LLEEG).

The LLEEG was set up by the Scottish Government's drug policy advisory group Partnership for Action in Drugs (PADS, since disbanded) to provide a pathway for the voices of people who have 'lived and living (current)' experience of problematic drug use. The term 'lived experience' was initially used to describe someone with experiential knowledge of drug treatment and recovery services. During the course of its development, it was acknowledged that people who currently use drugs should also be involved in the process, and the terminology was expanded to 'lived and living'. I was part of the first LLEEG meeting that started to 'disrupt' this term and my reflections on this specific point are as follows:

I found the process very moving - in regards to who is the drug user in this narrative it is most definitely the reformed user - those who have gone through the recovery process and are now 'clean'. Yet, at the same time there was a recognition that there are voices missing from the conversation - that of the living drug user (i.e. those who still use drugs and are not interested in stopping). 
Even with the awareness that the living experience is missing, there seemed to be an unwillingness to properly address the fact that we are only focusing on those whose drug use appears to have caused a lot of harm, to themselves and their families. When I tried to get clarification on whether they mean all drug users I was met with nods of agreement, but a silent feeling that I was trying to bang a drum for something that was not worth the time. (PADS LLEEG, Bring Your Voice, June 2017)

My attempt to get clarification on the exact kind of living experience is reflective of my personal agenda. I have found that there is general agreement that Scottish drug policy is directed towards those that appear to cause the most harm, and this is logical. The problem lies in the fact that drug policy, both reserved and devolved (criminal legislation is reserved to the UK Government), affects all drug users. As a person who has used drugs for decades, and interacted with many drug-using communities, I have seen and experienced this.

In this group, I engaged as a woman with lived experience of problem drug use. This experience came from being in a relationship with a man who was dependent on heroin, and who ultimately died as a result of his drug use. I represented the family member experience. However, I also wanted to engage as someone who had living experience of drug use, as a result of my recreational and medicinal use of cannabis, and occasional use of other drugs such as 3,4-Methylenedioxymethamphetamine (MDMA), psilocybin and cocaine. I found that when I relayed my experiences of problem drug use, my engagement and stories were given validation. However, when I tried to engage as a recreational current user, they were not. Once again it was subtle. It was not that I was silenced, but that the focus of the group was on drug harm, and therefore there was no space to talk about other kinds of drug use or drug users.

A final important note on this group: it was set up to provide pathways for the lived and living voice to be heard at the agenda-setting stage, specifically by choosing several representatives to sit on the executive committee of PADS. This, however, never happened. The group met three times and was then disbanded, as was PADS. What impact the group had on influencing policy is unknown, except for the inclusion of 'living experience' in the title, no feedback was ever communicated to the group, or evidenced by policy shifts as a result of their discussions. The result was a lack of trust of the Scottish government's commitment to engage with the lived and living experience voice.

\section{Typography of Drug User Participation}

Through my involvement with these groups I began to see a typography of drug user participation, ranging from the legitimate to the illegitimate.

\section{The RecoveredIRecovering Drug Users: Legitimate}

These users are people who are either in the recovery treatment system, or have recovered and are 'drug free' (or at least illicit drug free). People in this community 
are predominantly in recovery from opiates, alcohol and cocaine, although the term covers all behaviours considered to cause dependence (one of my interviewees identified as being in recovery from an eating disorder). They are the main staple of drug policy engagement and are considered important stakeholders in policy development.

The recovery story has been part of Scottish drug policy since the 2008 'Road to Recovery' (Scottish Government, 2008) strategy, and this has informed much of the participation work going forward. However, as one senior civil servant responsible for drug policy at the time commented:

I think the other thing that was interesting to me, and hadn't really been so [... as I] hadn't really had to think about it, was the number of people involved in this world that had actually been impacted by those issues themselves. So quite a lot of people declaring early on to me that they were in recovery and it became like a ... it was almost like they were more worthy than other people because of their lived experience. (Senior Civil Servant, interview, 2016)

I experienced the same when engaging with groups, particularly with the LLEEG. The legitimate drug consumer was one who had stopped using drugs and was now able to present their experience to the group. They used their experiences, sometimes from decades before, as their identity within the groups, yet challenged those of us who attempted to broaden out the narrative to include different kinds of drug users. As we saw, the lived experience expanded to include living experience, yet I only came across a handful of people within the group who identified with the living element, and those who did were either parents of children currently using drugs problematically, or were topping up their prescription with street drugs.

\section{The Sick Drug Users: Sometimes Legitimate}

The sick user is only legitimate in one context: the engagement of problematic drug users. The sick user is one who is currently using drugs problematically and may not want to stop, but needs to be engaged in order to provide pathways for recovery when they want it. In many areas drug dependency is considered a disease of the mind, and the narrative goes 'they are sick and need our help to get better' (off drugs).

However, in a different context the sick user has less legitimacy. In the context of using cannabis, psychedelics or MDMA, all drugs that have recently been shown to help in various physical and mental illness (see further Beckley Foundation, MAPS and Drug Science), users are not engaged with pro-actively, and in many cases engagement is made intentionally difficult. My experience of trying to engage policymakers and institutions responsible for patient engagement, such as the MCRS, was difficult when I was representing the medicinal cannabis user. Indeed, my involvement with this group, as seen above, resulted in my own legitimacy being questioned, and my persona of professional and objective policy 
expert became one of drug user lobbyist. As a result, my ability to access institutional policymakers and engagements was reduced.

\section{The Professional Drug User: Sometimes Legitimate}

The professional drug user is hard to find because of the stigma associated with drug use. In general, professionals (and by this I mean individuals who are part of an institutional profession such as academia, $3^{\text {rd }}$ sector, public bodies or are in the process of creating a professional career) do not disclose drug use as to do so would risk their career development. A good illustration of the consequences of drug use being discovered is the following story from one of my interviewees:

An incident happened and a doctor overdosed on heroin in this hospital, and it was really horrible because it was one of these things were his wife phoned up and said my husband's not come home, does anyone know where he is, that kind of thing, and he was found in a toilet. He was alive! And of course, somehow these things always seem to get on the front page of the Daily Record (tabloid newspaper) you know [laughs] so names, people get named and all that. So it was one of these organisational things that happened, 'oh my god', you know. And the organisation just decided they were gonna have this guy for breakfast, so they were gonna take him down a very very unpleasant disciplinary route.

And as the local addictions specialist I was asked to give my opinion with regard to this guy. And of course I gave the opinion which was he has a...without going into all the details there were many reasons why this had happened, it was all very understandable, it was all very explainable. And, when you're faced with people not being able to perform at work, in the NHS, you take them down one of two routes: it's either a disciplinary route, or it's a - as we would call it - a sick doctor route. I advised we should take him down the sick doctor route.

Wow. Light the torch paper, stand well back. I was in hearings, and it was ... so they were trying to say you can't possibly be a doctor and have had a drug problem. So, because people can't ... what they were really saying was people can't not have a drug problem any more, he's a heroin addict, he's going to take people's drugs and use them for himself ... that monster! So, it was really interesting 'cause I had to put ... you know it was one of those, you know, when you've got a career, you actually have to go 'hmmmm, okay, I'm gonna step over here now', and you have to go nut (no), this is my position, here's my position. (Addictions Specialist and senior government advisor, interview, 2016) 


\section{Anna Ross}

This story gives us insight into the professional implications of drug use, and the responses from the institution. What the narrator is telling us is that the institution was not able to respond compassionately, because they did not understand the complexity of drug use. Even with the advice of the specialist, they were unable to comprehend how someone can continue to be a professional once they have used drugs. While the potential for him to be considered a 'sick' doctor (legitimate) existed, this was not an option because of the publicity surrounding the case. From this, and many other anecdotes I came across, it has become apparent that there is a dichotomy between the professional and the drug user.

I experienced this dichotomy, and I hope to have gone some way to challenging it. My involvement in the policy process came about through SDPC, and my persona, as mentioned above, was one of an academic and professional. However, through the course of the engagements I became more vocal about my own drug use, thereby mixing my engagement as a professional and a drug user. The first time I informed a member of a larger institution that I used drugs I was met with that slightly startled flickering eye movement. I could see them processing this information and trying to make it match with their previous impression of me. It was a risky move, and I was advised against by several peers, but I felt I could not continue to engage and speak about drug users as if they were somehow 'other' to me. My relationship with institutional representatives did not change much after my disclosure, at least not at first, but I was still constrained in how I could participate, through the avenues described above. I have found that the policy identity that was cultivated as a result of disclosing lived experience, was a 'lived experience and professional policy expert' persona, both of whom are legitimate in my typology of participation. However, if I start engaging with the 'happy drug user' persona, I am not afforded the same weight in policy discussions.

These two stories show that in some contexts the professional drug user is considered a legitimate participant, although professionals who use drugs are generally not considered legitimate stakeholders in the process, or indeed legitimate professionals.

\section{The Happy Drug User: Never Legitimate}

The happy drug user is hardly seen in drug policy. The idea that someone takes drugs pleasure, and continues to be happy despite drug use, is not spoken about, and those who do are silenced. This silencing is subtle. Because of the focus on harm, all initiatives, meetings, engagements and documents come from this paradigm. Discussions on the pleasure of drugs are silenced by the focus on harm, and those who challenge this are considered to be indulging in personal agendas.

Yet, it's not so much that the happy drug user is ignored completely, but the tactic of sidestepping is practiced in order to silence the narrative. The concept of the non-problematic drug user is set out in the 2008 drug strategy (Scottish Government, 2008) where they define three broad categories: experimenters, regular users and problem users. It is the final category that drug policy appears to focus on. In private discussions of drug use between the drug policy communities, it is 
commonly accepted that the majority of drug users consume drugs with minimal harm, and do so for enjoyment. Yet, this acknowledgement is not acted upon once it has been expressed. This sidestepping sits alongside the concept of 'moral sidestepping', developed by Alex Stevens (2019).

In his article, Stevens (2019) examines why it is that despite recommendations from the Advisory Council on the Misuse of Drugs (ACMD) and other institutional bodies, initiatives that would reduce harm, such as drug consumption rooms and heroin-assisted treatment, are not being implemented. Stevens analysed parliamentary documents from 2016 to 2018 and found that there is a practice of moral sidestepping - that is, the acknowledgement of the evidence supporting the initiative (consumption rooms etc.) and a side step by stating their own moral belief that taking drugs should be strongly condemned. The result is inaction, based on the implication that to act is morally wrong (in a puritanical Christian sense) (Stevens, 2019). In Scotland, the excuse is that criminal sanctions are reserved, allowing policymakers to sidestep the tricky questions without addressing the issue head-on. I call this 'constitutional sidestepping'. By acknowledging but ignoring, a form of this tactic is successfully employed to dismiss the views of those who are not considered legitimate stakeholders in drug policy discussions.

While policymakers use tactics such as moral sidestepping and silencing to prevent broader discussions of drug use, another important factor for nonengagement of 'happy drug users' in the policy process is the criminal nature of the activity. Only those who are considered problematic users, and therefore excused from their drug-taking behaviour as a result of their lack of agency (addiction brought on by poverty/mental health/trauma and are unable to stop), are considered to be the legitimate focus of participation, and only marginally at this. To suggest that the wider drug-using population, the health worker that smokes joints, the nursery teacher that takes a bit of cocaine every now and then, the postman who goes to annual raves or the artist who indulges in lysergic acid diethylamide (LSD), are every bit as legitimate in the policy process as those who have serious problematic drug use, is to suggest that drug use per se is not the problem. This was apparent from the SDPC engagements where many participants who had used drugs, in the past and currently, did not feel able to openly admit it beyond the safety of a group governed by Chatham House Rules. ${ }^{1}$ The concept of a 'coming out' day was mooted, but once again many felt unable to put their careers and professional persona on the line. Indeed, one professional who is also a regular heroin user commented that if they came out, there was a very strong possibility the police would use their phone to get to their dealer. This is a very real concern and one that exists in the medicinal cannabis community too. The campaign leader for MCRS openly grows her own cannabis plants for her medicine. The police know it, because through our engagement with the police she has spoken about it. However, this has left her vulnerable to criminal prosecutions should the police decide to use this information to make another 'drugs bust'.

\footnotetext{
${ }^{1} \mathrm{~A}$ form of confidentiality developed by Chatham House. See further https://www. chathamhouse.org/chatham-house-rule.
} 


\section{Final Thoughts}

As a result of policy being focussed on drug-related harm, participation in policy is restricted to certain channels where the government feel they can be most effective. They, therefore, focus on the harms stemming from problematic use and participatory processes to engage this affected community are developed along these lines.

Critical drug theory seeks to challenge this focus by highlighting the silence around drug use for pleasure and self-medication, and the oppression of certain groups in society. It is a work in progress and will need to be developed and tested in order for it to become part of the critical theory landscape. However, it is grounded in critical thought with the underlying premise that the foundations of drug policy, both national and international, are based on ideological reasoning that is often used to suppress and silence those who seek to challenge the status quo. Subjecting policies to critique and critical evaluation, such as research into the impact drug laws have on individuals and society (as opposed to the impact drug use has), should be advocated, along with public engagement on the complexity of drug use and harm.

Yet, because the dominant narrative surrounding drug use is one of totemic toughness (Stevens, 2009), and people who use drugs are viewed as problems to be dealt with as a result of the harm stemming from their use, those whose livelihoods would be put at risk if they were considered to lack personal control and agency will not raise their heads above the parapet. This is the fundamental problem facing public participation in drug policy-making; only those willing to take the risk, or who have nothing to lose by 'coming out', will be engaged at this stage. These drug consumers are invariably already part of the system because they have had to identify as a drug user in order to access medical and social support. The focus on harmful drug use masks the widespread use of drugs by a variety of different communities, and prevents honest dialogue about the impact drug use and drug policy has on society as a whole. 